\title{
The Relationship Of The Methodological Support Of The Educational Process, The Level Of Preparedness Of Students And The Quality Of Teaching Staff In The Russian Language Based On Testing
}

\author{
Xodjaniyazova Aygul Ayitmuratovna- Candidate of Pedagogical Sciences, Associate Professor \\ Genjebaeva Gulbaxar Kurbanbaevna - senior lecturer \\ Tolegenova Gulaym Janabergenovna - senior lecturer \\ Tursinova Madina Muxanbetjanovna - assistant teacher \\ Abdullaeva Roza Abdullaevna - assistant teacher \\ Nukus State pedagogical institute named after Ajiniyaz \\ The Republic of Uzbekistan
}

\begin{abstract}
In this article, the author considers the educational process, in particular, teaching Russian language in schools, as well as the relationship of the methodological support of the educational process, the level of preparedness of students and the quality of teaching staff in the Russian language based on testing.
\end{abstract}

Keywords:

Russian language, teaching methodology, educational process, school, methodical literature, testing, preparedness level, school education, multinational composition.

Article Received: 18 October 2020, Revised: 3 November 2020, Accepted: 24 December 2020

\section{INTRODUCTION}

To teach Russian language, schools in Karakalpakstan with the Russian language of instruction differ in the multinational composition of students with a predominance of children representatives of Turkic nationalities (Karakalpaks, Kazakhs, Uzbeks, Tatars, Turkmens, etc.), there are errors in these students' explanations the interfering influence of the mother tongue, many times harder. Therefore, it is necessary to pose and resolve the methods of teaching Russian language in the Karakalpak school in a different way.

The Russian language in the post-Soviet space is the main intermediary language, the language of building bridges of cultures, bridges of science and education, therefore, it remains a compulsory subject of school and university education in the Republic of Uzbekistan and is taught on the basis of teaching Russian as a nonnative language. [1. from. 73]. In the CIS countries, including Uzbekistan and Karakalpakstan, the Russian language should continue to have educational status as a compulsory subject for school and university education. In schools and academic groups of universities with Uzbek, Karakalpak-teaching languages, the teaching methodology should completely dominate - Russian as a non-native language. [2.p. 13].

The first condition for the correct formulation and resolution of questions about the methodology of teaching Russian language in the Karakalpak school is an understanding of the general goals and objectives of the school. Thus, the analysis of the program provides the basis for the initial orientation in posing the questions of the methodology. Consequently, the construction of the methodology of school teaching of the Russian language should proceed from the content of the "features" of the entire system of the Russian language. The methodology should find and point out such methods of teaching Russian language that would teach Karakalpak students the real, complete Russian language, tell them strictly 
scientific information, and give exact norms of speech practice.

At the same time, the quality of education in one direction or another is determined by its results. The results of modern school education in the field of studying Russian language, unfortunately, do not adequately meet the requirements of the State Educational Standards of General Education and the curriculum. As the analysis of testing materials shows, high school students in secondary schools do not have sufficient knowledge of the norms of the Russian literary language (pronunciation, lexical, grammatical, stylistic), the norms of Russian speech etiquette, and are not able to put them into practice.

It should also be noted that the real status of the subject "Russian language" in the school system is not at the proper level yet. Studying it is far from always combined with interest in the subject and is often associated in the minds of schoolchildren only with memorization of the rules and the need to pass entrance tests at the university.

The negative factors noted above require serious critical analysis in the field of teaching Russian language in schools and identify the causes of negative trends that characterize the development of language education in our country.

When teaching Russian in high school, more attention should be paid to linguistic and methodological factors related to the forms and methods of educational and methodological support of the teaching process itself, i.e. the quality of programs, textbooks, teaching aids, reference books, etc.

Learning tools can play a positive role if applied in the system, if their interconnectedness and interdependence are taken into account in the process of solving specific educational problems.

A school textbook is a special book that sets out the basics of scientific knowledge in the Russian language and is designed to achieve educational goals. It must comply with state educational standards, modern requirements for the student.

Speaking about educational programs of study, we would like to single out one of its most important characteristic features that deserve attention - focused orientation on a wide specialized profile by introducing educational and special subjects of a wide profile, closely interconnected in the structure of the educational process, as well as providing a synthesis of the language being studied with history, culture, with a socio-economic structure and other problems of the country's development.

The main functions of the textbook are informational, transformational, systematizing, educational. Moreover, all the materials in the textbook should be aimed at developing students' ability to independently and creatively evaluate language facts and use them in the communication process. [3.p.14].

The state educational standard and textbook should have a common system of concepts, facts, a common sequence of their study. But in the textbook (in contrast to the standards), the interpretation of linguistic phenomena should be given, the content of the concepts being studied should be clarified, exercises on consolidation and creative application of knowledge should be included. The textbook determines the amount of information about the concepts being studied, contributes to the formation of the necessary ways of activity for students. The textbook should include the following structural components: theoretical information about the language in the form of texts and non-textual components: for organizing work (questions, tasks), illustrative material, and the orientation (indexes, table of contents, headings).

Texts about the language constitute the main content of Russian language textbooks. They are divided into primary and secondary. The main texts describe the facts and phenomena of language and speech, give definitions and concepts, list their main features, draw conclusions and generalize, offer tasks and exercises, on the basis of which a system of skills 
is formed, and rules are derived. Additional texts provide reference materials, notes, clarifications, etc. The apparatus of organization of work includes, first of all, questions and tasks oriented toward organizing student observations on facts and phenomena of the language, contributing to the systematization and generalization of what has been studied, directing students to form key skills.

Existing textbooks should reflect the structural-semantic direction in linguistics, according to which the phenomena and facts of the language are described in three aspects, in three directions: form (structure), meaning (semantics), function (use in speech). Consequently, any linguistic unit to be studied is considered from three sides: these are its structural indicators, its significance and characteristics of use in speech practice.

The drawback of the current Russian language textbooks for secondary schools in Karakalpakstan is that the linguistic facts in them are not presented in the totality of their manifestations, not all sections of the language are described. Some sections of the Russian language school course need to be modernized and deepened (phonetics, orthoepy, stylistics).

Thus, the textbook should be a means of mastering knowledge, skills. A significant place in it should be occupied by material aimed at teaching schoolchildren the skills to apply the acquired knowledge in the process of communication, speech practice (tasks, exercises, tests).

Exercises, tasks, tests should be focused on the development of cognitive activity of students, on the formation of experience in creative activity. They should be productive and have a search character, that is, focus on the formation of skills to apply the acquired knowledge in a new situation, independently analyze the facts of the language, draw conclusions and generalizations. Examples of such tasks are tests.

In our opinion, many of the shortcomings in teaching Russian language in a comprehensive school are explained by shortcomings in the content of existing programs and textbooks in the
Russian language, as well as by the imperfection of the forms and methods of work used in the educational process.

First of all, it should be noted that in itself the problem of creating a modern high-quality school textbook is extremely complex both in theoretical and practical terms. Many linguistic and methodological aspects of this problem require basic research. Moreover, serious disagreements among specialists are raised in the definition of goals, objectives and the specific content of education in the field of studying Russian language (both native and non-native (second)) in schools. Moreover, opinions here range from the requirements of a sharp reduction in theoretical information about the Russian language and the limitation of the goals and objectives of language education to tasks of a purely pragmatic nature - to the requirements of a significant expansion of the volume of language education, the strengthening of its fundamental nature, the appropriate use of comparative characteristics, giving textbooks more personal oriented orientation. [4.c. 49]

It cannot be said that the school textbook is a very specific genre of scientific and methodological literature, requiring special personal qualities of the author and special preparedness in the field of linguistics, psychology and methodology. The noted difficulties cannot but affect the quality of modern textbooks in the Russian language, but they do not cross out the achievements that are available today in the school system of Karakalpakstan in the field of educational and methodological support in the subject "Russian language".

It seems that one of the main ways to improve modern school textbooks in the Russian language and improve the quality of teaching it in high school is the optimal implementation of the ideas embodied in the modern concept of education in the field of the Russian language in the educational and methodical literature and practice of school teaching Russian language.

In order to check the level of knowledge of high school students and teachers, the availability 
of textbooks, teaching aids and their quality, we conducted monitoring. The monitoring results showed (see Fig. 2.8. On page 85) that the provision of students with textbooks and teaching aids in Nukus is $95.3 \%$ and, accordingly, a high level of knowledge $(74.5 \%)$. Low rates in Turtkul $-19.8 \%$ and $37 \%$ respectively. [5.p.77]

Table 1. The level of students training, methodological security and quality of teaching

\begin{tabular}{|c|c|c|c|c|}
\hline Code & Cities & $\begin{array}{c}\text { Methodological } \\
\text { support }\end{array}$ & Teaching quality & Student level \\
\hline 1 & Nukus & 95,3 & 86 & 74,5 \\
\hline 2 & Kungrad & 38 & 75 & 67 \\
\hline 3 & Khojeyli & 28 & 67 & 52 \\
\hline 4 & Tahiatash & 26 & 60 & 39 \\
\hline 5 & Chimbay & 24 & 63 & 41 \\
\hline 6 & Turtkul & 19,8 & 59 & 37 \\
\hline 7 & Beruni & 21 & 67 & 48 \\
\hline
\end{tabular}

The above indicators prove the interdependence between the scientific and methodological support of the educational process and the quality of student training.

The results of the study showed:

1. Students of secondary schools of Karakalpakstan are provided with modern textbooks and educational and methodical literature on the Russian language and literature by an average of $38.4 \%$.

2. As a result of this, in the educational process a large amount of time is spent on unproductive activities (taking notes of lectures, transcribing, etc.)

Nowadays, the provision that the solution of complex problems of improving the quality of education and training of students to a decisive degree depends on the teacher does not require evidence. To paraphrase the old, but so modern thought of D.I. Pisarev, we can say: "In education, the whole thing is who the teacher is." [6.p. 54].

Teaching Russian language, the development of oral and written speech of students require a vocabulary teacher to master the skills and abilities necessary for this work, competence, a creative approach to the work of students, knowledge and practical use of the best practices of colleagues. Improving the quality of lessons, the implementation of continuity and perspectives in learning, the system of repetition and consolidation of educational material, the organization of students' independent work at all stages of education, the control of knowledge, skills and mutual assistance of students, the implementation of a single spelling and speech mode at school - all these and other methodological problems require constant attention of teachers.

An important element in the work of teachers is continuing education. Teachers' work plans should be drawn up taking into account the specifics of schools and in accordance with the modern goals and objectives of teaching.

One of the main tasks of teachers should be self-improvement. The teacher must purposefully and rationally build a system of lessons, apply the most effective innovative teaching methods and techniques.

Sometimes a young specialist, solving one of the problems, misses the others or resolves specific issues of the next topic of the lesson, puts him in the background, or theorizes too much in the lesson, is carried away by general questions of the methodology. Such inattention to pedagogical 
"nuances" can seriously damage the learning process.

Our testing of Russian language and literature teachers in 8 cities of the Republic of Karakalpakstan (Nukus, Beruni, Turtkul, Kungrad, Chimbay, Khojeyli, Takhiatash, Kegayli) confirmed that the quality of students' knowledge is largely determined by the level of knowledge of teachers themselves. High indicators in solving tests by teachers were obtained in regions such as Nukus and Kungrad, respectively, high levels of knowledge were demonstrated by students in the same regions. Poor knowledge of teachers in Turtkul and
Takhiatash naturally affected the knowledge of their students. If the teacher does not have an adequate level of the sections "Phonetics", "Syntax", "Stylistics", then the students do not answer the questions in the same sections weakly. The mentioned idea confirms a comparative analysis of the responses of teachers and students to test tasks (see Table 1 and Fig. 1).

In connection with the results of testing students over the past years, attention should be paid to the factors of preparation for the final testing in Russian of the teachers themselves. In this plan:

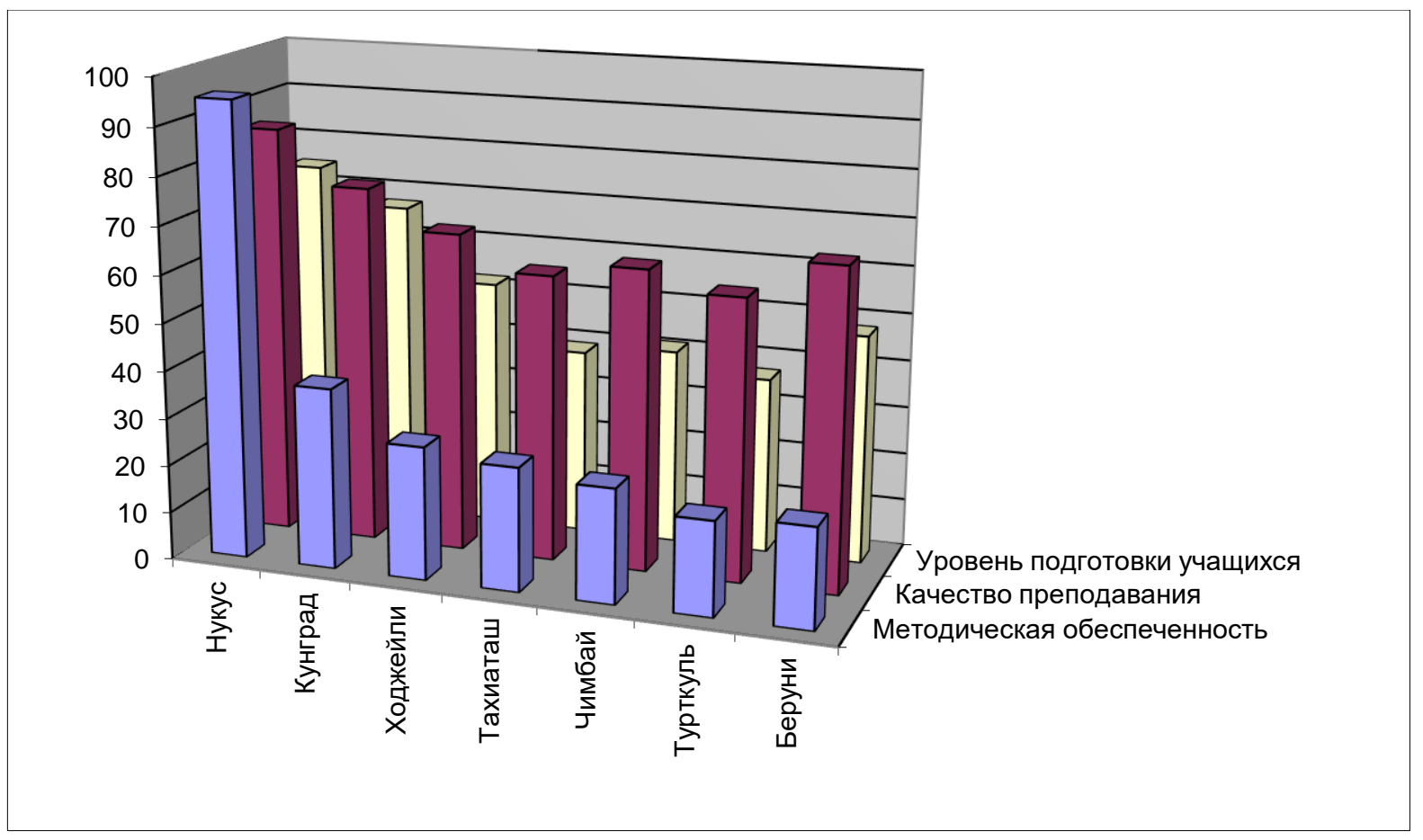

Fig. 1 Level of student training, methodological support and quality of teaching

1. It is necessary to aim the Russian specialists on the preparation for teaching, focused on quality indicators based on the results of entrance tests:

a) familiarize them with the uniform requirements of the state educational standard, programs in the Russian language to the level of knowledge, skills of students;

b) recommend a deeper study of modern curricula and advanced technologies for teaching Russian language;

c) hold a teacher's workshop on the methodology for compiling and conducting tests, on identifying, correcting, designating grammatical and phonetic errors in students' answers;

d) create methodological developments taking into account modern criteria for teaching Russian language.

2. To form at schoolchildren the key skills verified by testing; purposefully devote part of the time to lessons to control the knowledge, abilities and skills of students by the testing method, primarily to consolidate:

a) the ability to analyze the styles of the language; 
b) the ability to draw independent conclusions from theoretical material; c) the ability to use in their speech a variety of grammatical forms and constructions, as well as the lexical richness of the language;

d) possession of spelling and punctuation skills;

e) knowledge of the norms of the modern Russian literary language.

Improving pedagogical skills is a multifaceted comprehensive work. It should be based on the best experience of innovative teachers, supported by its own "ideas" and "finds". In order to put the methodical work in the school on a solid foundation and ensure its efficiency, good quality, it is necessary to first determine the strategic directions of this work, coordinate the implementation of basic activities in time, analyze and monitor their effectiveness and quality.

Our observations of the educational process and an experimental survey of the activities of students and teachers in Karakalpakstan allow us to conclude that a certain part of the teachers are familiar with the content and structure of the tests, and is working to prepare students for them. At the same time, one cannot fail to note the following facts:

1. Some teachers find it difficult to complete the tests he proposed.

2. In preparing students for tests, the emphasis is often placed on training them to perform as many test cases as possible (mechanical memorization), rather than on a solid study of program material on the main sections and topics of the Russian language course, aimed at developing the language competence of students.

3. Reflection is not provided for and is not carried out, on the basis of which further work should be built to prepare students for the test.

4. Tests should be made in such a way that they are readable and satisfy the rules of the Russian language; not every teacher is able to formulate a question so that it is clearly perceived by all.
5. Different students at different times can use different textbooks in preparation for testing, where the same question is covered with varying degrees of completeness and clarity of presentation. The change or temporary substitution of the teacher leads students to the need to somehow "fit in" with the work style of the new teacher, which, perhaps otherwise (either too complicated or, conversely, is too simple and affordable), explains the new grammatical material and which estimates it differently the degree of difficulty of test tasks in relation to students with different levels of training.

6. Students who know the training material better than others, as a rule, are better than others and predict for themselves the time required to complete the tasks. Therefore, they first perform simple tasks, and complex ones are left "for later". This can lead to an erroneous understanding of the degree of difficulty of the tasks. At first glance, simple tasks can be the most difficult and require more time to complete.

7. And, finally, test methods do not mean replacing the teacher and his personal experience, but rather are designed to help him rationalize his work and create the opportunity to focus more deeply on technology to improve the quality of teaching.

An experimental study showed that the level of students' knowledge depends on many factors, but, first of all, on the quality of teacher training.

\section{References}

[1] Djusupov M., Sociolinguistic and linguodidactic problems of language as a means of communication and a subject of study-Russian Studies in the CIS.-SPb :: Zlatoust, 2002. S. 73.

[2] Djusupov M., Kudakaeva AZ, Majitaeva Sh. Phraseology of the Russian language: linguistic and methodological problems Tashkent, "Fan", 2008. P.14.

[3] Andriyanova V.I. Didactic-psychological requirements for a modern textbook for a reformed school. -T., 1988 .-- P.14.

[4] Textbook of the third millennium: 
creation, publication, distribution: Materials of the III International scientific and practical conference. I-part. -Almaty, 2003. Speeches by M.D.Jusupov, V.I. Andriyanova, D.D. Jalalova and other scientists.

[5] Khodjaniyazova A.A. Modern methods of knowledge control in teaching Russian language - Nukus: Karakalpakstan, 2009. P. 28. 